\title{
Indução de fitoalexinas por preparações de leveduras, Trichoderma e óleo essencial de Cymbopogon citratus Stapf.
}

\author{
Micaele Rodrigues de Souza ${ }^{a}$, Laiza Priscila dos Santos ${ }^{a}$, Alessandra Macedo Barros ${ }^{a^{*}}$, \\ Gil Rodrigues dos Santos a , Gleys Kellen Aquino Moraes a, Luana Fernandes Ferraz ${ }^{a}$, \\ Valeria Bastos de Araújo $^{a}$, Talita Pereira de Souza Ferreira ${ }^{a}$
}

\footnotetext{
${ }^{\text {a }}$ Universidade Federal do Tocantins (UFT), Brasil

*Autor correspondente (macedo46@outlook.com)
}

\section{N F O}

Keywords

resistance

gliceolin

deoxyanthocyanins

Palavras-chaves

resistência

gliceolina

deoxiantocianidinas

\begin{abstract}
A B S T R A C T
Induction of phytoalexins by preparations of yeasts, Trichoderma and Cymbopogon citratus Stapf. essential oil

Phytoalexins may be induced by biotic and abiotic agents known as elicitors. In this work, you can evaluate the potential of the essential oil of Cymbopogon citratus Stapf., From the fungus Trichoderma sp. and yeast for phytoalexin induction in sorghum (Sorghum bicolor (L.) Moench) and soybean cotyledons (Glycine max L.) mesocotyls. As yeast Sacharomyces cerevisiae, Sacharomyces boulardii and fungus Trichoderma sp. were tested on samples $0.5 ; 5 ; 25 ; 50 ; 75$ and 100\%. Cymbopogon citratus Stapf oil. at $625,1250,2500,5000$ and $7500 \mu \mathrm{g} / \mathrm{mL}$ configurations. The trade product accorda ${ }^{\circledR}$ was used as a positive control for soybean testing and Biozyme ${ }^{\circledR}$ for sorghum. Sterile distilled water was tested negative for testing on cultures as well as cultures. As two resistance induction methodologies in different sera are not as follows: in the first the mesocotyls were excised $0.5 \mathrm{~cm}$ above the listener node and application tubes, we applied $1 \mathrm{~mL}$ of the sample to be tested. The second time the seedlings are sprayed $2 \mathrm{~mL}$ of the samples are tested in different sizes. All evaluated substances promote or accumulate phytoalexins in soy and sorghum. Oil treatment was the most efficient, however, in the case of sorghum, as high oil temperatures caused inhibition of seedling growth. The second sorghum resistance induction methodology yields the best results of the first one due to the large number of phytoalexins and the possibility of observing the seedling reaction to each treatment.
\end{abstract}

\section{R E S U M O}

As fitoalexinas podem ser induzidas por agentes bióticos e abióticos conhecidos como eliciadores. Neste trabalho, objetivou-se avaliar o potencial do óleo essencial de Cymbopogon citratus Stapf., do fungo Trichoderma sp. e de leveduras na indução de fitoalexinas em mesocótilos de sorgo (Sorghum bicolor (L.) Moench) e cotilédones de soja (Glycine max L.). As leveduras Sacharomyces cerevisiae, Sacharomyces boulardii e o fungo Trichoderma sp. foram testados nas concentrações 0,$5 ; 5 ; 25 ; 50 ; 75$ e $100 \%$. O óleo de Cymbopogon citratus Stapf. nas concentrações de 625, 1250, 2500, 5000 e $7500 \mu \mathrm{g} / \mathrm{mL}$. O produto comercial acorda ${ }^{\circledR}$ foi utilizado como testemunha positiva para os testes em soja e o Biozyme ${ }^{\circledR}$ para sorgo. Água destilada esterilizada foi testemunha negativa para os testes em ambas as culturas. As duas metodologias de indução de resistência em sorgo diferiram-se no seguinte: na primeira os mesocótilos foram excisados $0,5 \mathrm{~cm}$ acima do nó escutelar e colocados em tubos, contendo $1 \mathrm{~mL}$ da amostra a ser testada. Na segunda as plântulas receberam aspersão de $2 \mathrm{~mL}$ das amostras a serem testadas em diferentes concentrações. Todas as substâncias avaliadas promoveram o acúmulo de fitoalexinas em soja e sorgo. O tratamento com o óleo foi o mais eficiente, porém, no caso do sorgo, as altas concentrações de óleo provocaram inibição no crescimento da plântula. A segunda metodologia de indução de resistência em sorgo gerou melhores resultados que a primeira devido ao grande acúmulo de fitoalexinas e à possibilidade de observação da reação da plântula a cada tratamento. 


\section{INTRODUÇÃO}

$\mathrm{Na}$ agricultura, as doenças causadas nas culturas por fungos, bactérias e vírus podem causar perda de rendimento bastante elevado. Muitas estratégias têm sido desenvolvidas para evitar os danos causados por esses agentes patogênicos, como por exemplo, técnicas de evasão, rotação de culturas, manejo do solo, nutrição de plantas e uso de variedades resistentes. Além disso, produtos químicos são amplamente aplicados nas plantações, porém, especialmente na agricultura orgânica, é necessário substituir tais produtos por métodos biológicos de controle de doenças e pragas (Tamm et al., 2011).

Dessa forma, compostos derivados de plantas com atividade antimicrobiana são cada vez mais explorados para uso na preservação e melhoria da qualidade dos alimentos (Ejike, Gong e Udenigwe, 2013). Muitos mecanismos de defesa das plantas contra microrganismos patogênicos envolvem a produção de metabolitos secundários, que podem ser constitutivos ou induzíveis (Pedras e Ahiahonu, 2005). Os constitutivos são substâncias que já estão presentes nos tecidos sadios das plantas em altas concentrações e as induzíveis são substâncias produzidas em decorrência de algum estresse sofrido pela planta (Fadini et al., 2004; Thaler et al., 1999).

As fitoalexinas são substâncias induzíveis de defesa das plantas e têm sido estudadas há mais de um século (Peters, 2006). Os agentes de origem biótica ou abiótica que são capazes de induzir a resposta de defesa nas plantas contra patógenos são chamados de eliciadores (Stangarling et al., 2010). Dentre estes estão os microrganismos como por exemplo leveduras e os óleos essenciais, definidos como compostos voláteis que são meios não favoráveis para o crescimento de diversas bactérias e fungos (Bazargani e Rohloff 2016; Dorman e Deans, 2000; Zanardo, Pascholati e Fialho, 2009).

Muitas pesquisas já foram feitas mostrando o potencial de leveduras no controle de doenças em plantas de soja, milho, sorgo, eucalipto, maracujá e pepino (Stangarlin et al., 2010; Zanardo, Pascholati e Fialho, 2009). E entre os óleos essenciais citados como agentes antifúngicos está o óleo de Cymbopogon citratus (DC) Stapf (capim-limão) que é reconhecido também pelas suas propriedades anti-inflamatórias, repelente para mosquito e inseticida (Costa et al., 2016). Sendo assim, neste trabalho, o potencial de diversos tratamentos, tais como preparações do fungo Trichoderma sp., leveduras e óleo essencial de Cymbopogon citratus Stapf. foram analisados como indutores de fitoalexinas em mesocótilos de sorgo e cotilédones de soja.

\section{MATERIAL E MÉTODOS}

\section{Obtenção de células de Saccharomyces boulardii}

A obtenção das células de $S$. boulardi foi realizada a partir do produto comercial Florent $200 \AA$ (Cifarma). Com esse propósito, $100 \mathrm{mg}$ do produto foram colocados em $10 \mathrm{~mL}$ de água destilada esterilizada e, dessa suspensão, foi feito o isolamento em meio de cultivo BDA (batata-dextrose-ágar) sólido e a incubação no escuro a $36{ }^{\circ} \mathrm{C}$ por 4 dias. Após 4 dias, as células isoladas foram repicadas para $200 \mathrm{~mL}$ de meio de cultivo YEPG (dextrosepeptona-extrato de levedura) líquido esterilizado e mantidas sob agitação (150 rpm), no escuro e a 36 ${ }^{\circ} \mathrm{C}$ durante 7 dias.

\section{Obtenção de células de Saccharomyces cerevisiae}

As células de $S$. cerevisiae foram obtidas a partir do produto comercial Fermento Biológico seco instantâneo (Fleischmann ${ }^{\circledR}$ ). Para tanto, $100 \mathrm{mg}$ do produto foram colocados em $10 \mathrm{~mL}$ de água destilada esterilizada e, a partir dessa suspensão, foi realizado o isolamento em meio de cultivo BDA (batata-dextrose-ágar) sólido e incubação no escuro a $36{ }^{\circ} \mathrm{C}$ por 4 dias. Após 4 dias, os isolados de $S$. cerevisiae foram repicados para $200 \mathrm{~mL}$ de meio de cultivo YEPG (dextrose-peptona-extrato de levedura) líquido esterilizado e mantidos sob agitação (150 rpm), no escuro e a $36^{\circ} \mathrm{C}$ durante 7 dias.

\section{Obtenção de células de Trichoderma $\mathbf{s p .}$}

O produto comercial Agrotrich ${ }^{\circledR}$ (Agrosafra Sementes) foi utilizado como fonte para a obtenção das células de Trichoderma sp. Para isso, $100 \mathrm{mg}$ do produto foram colocados em $10 \mathrm{~mL}$ de água destilada esterilizada e, a partir dessa suspensão, foi realizado o isolamento em meio de cultivo BDA (batata-dextrose-ágar) sólido e incubação no escuro a $36{ }^{\circ} \mathrm{C}$ por 4 dias. Após 4 dias, os isolados foram repicados para $200 \mathrm{~mL}$ de meio de cultivo BDA líquido esterilizado e mantidos sob agitação (150 rpm), no escuro e a $36{ }^{\circ} \mathrm{C}$ durante 7 dias.

\section{Obtenção do óleo essencial de $C$. citratus Stapf.}

As folhas de $C$. citratus Stapf. foram coletadas no Campus de Gurupi/Universidade Federal do Tocantins. Empregou-se o método de hidrodestilação e utilizou-se um aparelho de Clevenger modificado adaptado a um balão de fundo redondo com capacidade de 1 litro (Guimarães et al., 2008). O processo de extração foi realizado em um período de 2 
horas, mantendo a solução em ebulição. Após, coletou-se o hidrolato, que foi centrifugado em centrífuga de cruzeta horizontal a $900 \mathrm{~g}$ por 5 minutos. O óleo foi retirado com o auxílio de uma pipeta de Pasteur e acondicionado em frasco de vidro âmbar.

Preparação das amostras a serem testadas

As células de $S$. cevevisiae, $S$. boulardii e Trichoderma sp. foram preparadas nas concentrações de 0,$5 ; 5 ; 25 ; 50 ; 75$ e $100 \%$, enquanto que o óleo de $C$. citratus Stapf. foi utilizado na concentração de $625,1250,2500,5000$ e $7500 \mu \mathrm{g} / \mathrm{mL}$.

\section{Obtenção da testemunha positiva}

Para a obtenção do controle positivo, utilizou-se quatro ativadores de resistência sistêmica comerciais, sendo eles Phytogard $\AA$, Biozyme ${ }^{\circledR}$, Yantra ${ }^{\circledR}$ e Acorda ${ }^{\circledR}$. Todos foram testados na concentração de $1250 \mu \mathrm{g} / \mathrm{mL}$.

\section{Ensaio para a indução de fitoalexina em cotilé- dones de soja}

Sementes de soja (Glycine max L.), cultivar Monsoy 8644-IPRO (Intacta ${ }^{\circledR}$ ), foram desinfetadas por 10 min em hipoclorito de sódio $1 \%$ e lavadas em água destilada. Posteriormente, as sementes foram semeadas em duas bandejas contendo areia autoclavada (à $121^{\circ} \mathrm{C}$ e $1 \mathrm{~atm}$ por $20 \mathrm{~min}$ ). As bandejas foram deixadas em casa de vegetação por 10 dias e os cotilédones foram destacados em seguida para a realização dos ensaios (Stangarlin et al., 2010).

Os cotilédones foram colocados em placas de petri de $120 \mathrm{~mm}$ de diâmetro, onde cada placa continha três cotilédones e duas folhas de papel filtro esterilizadas e umedecidas com água destilada esterilizada. Cada cotilédone foi cortado em pequenos fragmentos, os quais foram tratados com $100 \mu \mathrm{L}$ das amostras a serem testadas. As placas permaneceram incubadas à $25^{\circ} \mathrm{C}$, no escuro, por $20 \mathrm{~h}$. Na sequência, os cotilédones foram pesados e colocados em erlenmeyers contendo $10 \mathrm{~mL}$ de água destilada esterilizada, os quais foram deixados sob agitação orbital $(150 \mathrm{rmp})$ durante $1 \mathrm{~h}$ para que ocorresse a extração dos pigmentos (Meinerz et al., 2008; Stangarlin et al., 2010).

Por fim, os cotilédones foram retirados dos erlenmeyers e a absorbância do sobrenadante foi lida em espectrofotômetro à $285 \mathrm{~nm}$ (Meinerz et al., 2008). Água destilada esterilizada foi utilizada como testemunha negativa e o ativador de resistência comercial Acorda ${ }^{\circledR}$ foi a testemunha positiva (Stangarlin et al., 2010).

\section{Ensaio para a indução de fitoalexinas em meso- cótilos de sorgo (metodologia 1)}

Sementes de sorgo [Sorghum bicolor (L.) Moench], cultivar Buster (Atlântica Sementes $\left.{ }^{\circledR}\right)$, foram colocadas em hipoclorito de sódio $1 \%$ por 15 minutos e posteriormente foram lavadas em água destilada esterilizada. Em seguida, as sementes foram depositadas em folhas de papel de germinação umedecidas sendo enroladas e encubadas no escuro à $28{ }^{\circ} \mathrm{C}$ no período de 4 dias para que ocorresse a germinação (Stangarlin et al., 2010).

Após esse período, as plântulas formadas foram primeiramente expostas a luz por $4 \mathrm{~h}$ para que houvesse a paralização da elongação dos mesocótilos. $\mathrm{Na}$ sequência, os mesocótilos foram excisados 0,5 $\mathrm{cm}$ acima do nó escutelar e colocados em tubos para microcentrífugas (3 mesocótilos por tubo) contendo $1 \mathrm{~mL}$ da amostra a ser testada. Os tubos foram mantidos sob a luz fluorescente, a $25^{\circ} \mathrm{C}$, por $60 \mathrm{~h}$. Posteriormente, os mesocótilos foram retirados dos tubos, pesados e colocados em novos tubos contendo $1,4 \mathrm{~mL}$ de metanol acidificado $80 \%$ $(0,1 \% \mathrm{HCl} ; \mathrm{v} / \mathrm{v})$. Estes foram mantidos resfriados a $4{ }^{\circ} \mathrm{C}$ por $96 \mathrm{~h}$ para a extração dos pigmentos. A absorbância foi lida a $480 \mathrm{~nm}$ (Nicholson, Jamil, Snyder e Lue, 1988; Motoyama,Schwan-estrada, Stangarlin, Fiori-tutida e Scapim, 2003; Stangarlin et al., 2010). Água destilada esterilizada e o ativador de resistência comercial Biozyme ${ }^{\circledR}$ foram utilizadas como testemunhas negativas e positivas, respectivamente.

\section{Ensaio para a indução de fitoalexinas em meso- cótilos de sorgo (metodologia 2)}

Sementes de sorgo [Sorghum bicolor (L.) Moench], cultivar Buster (Atlântica Sementes $\left.{ }^{\circledR}\right)$, foram colocadas em hipoclorito de sódio $1 \%$ por 15 minutos e posteriormente foram lavadas em água destilada esterilizada. Em seguida, as sementes foram depositadas em folhas de papel de germinação umedecidas e as folhas foram enroladas e colocadas dentro de beckers na posição vertical. Em seguida, as sementes foram incubadas no escuro a $28^{\circ} \mathrm{C}$ no período de 4 dias para que ocorresse a germinação (Stangarlin et al., 2010).

Após esse período, as plântulas formadas foram primeiramente expostas a luz por $4 \mathrm{~h}$ para que a houvesse a paralização da elongação dos mesocótilos. Na sequência, as plântulas receberam aspersão de $2 \mathrm{~mL}$ das amostras a serem testadas em diferentes concentrações. Água destilada esterilizada foi utilizada como testemunha negativa, enquanto que o ativador de resistência comercial Biozyme ${ }^{\circledR}$ foi a testemunha positiva. As plântulas foram mantidas 
sob a luz fluorescente, a $25^{\circ} \mathrm{C}$, por $60 \mathrm{~h}$. Posteriormente, os mesocótilos foram retirados, excisados, pesados e colocados em tubos para microcentrífuga contendo $1,4 \mathrm{~mL}$ de metanol acidificado $80 \%$ $(0,1 \% \mathrm{HCl} ; \mathrm{v} / \mathrm{v})$. Estes foram mantidos resfriados a $4{ }^{\circ} \mathrm{C}$ por $96 \mathrm{~h}$ para a extração dos pigmentos (BONALDO, 2005). A absorbância foi, então, lida a 480nm (Nicholson, Jamil, Snyder e Lue, 1988; Stangarlin et al., 2010).

\section{RESULTADOS E DISCUSSÃO}

\section{Obtenção da testemunha positiva}

Dentre os ativadores de defesa das plantas testados, o Acorda ${ }^{\circledR}$ foi o que induziu maior produção de gliceolina em cotilédones de soja, induzindo $59,99 \%$ mais do que o ativador menos eficiente, Yantra ${ }^{\circledR}$ (Figura 1A). Dessa maneira, utilizou-se o produto comercial Acorda ${ }^{\circledR}$ como testemunha positiva para os testes em soja.

Para os testes com sorgo, determinou-se que o ativador Biozyme ${ }^{\circledR}$ gerou melhores resultados para a indução de flavonoides 3-deoxiantocianidinas em ambas as metodologias, sendo que os gráficos demonstraram comportamentos semelhantes. Assim como no teste com a soja, Yantra ${ }^{\circledR}$ foi o produto com menor indução em sorgo (Figura $1 \mathrm{~B}$ e C). Portanto, para os testes com sorgo, Biozyme ${ }^{\circledR}$ foi utilizado como testemunha positiva.

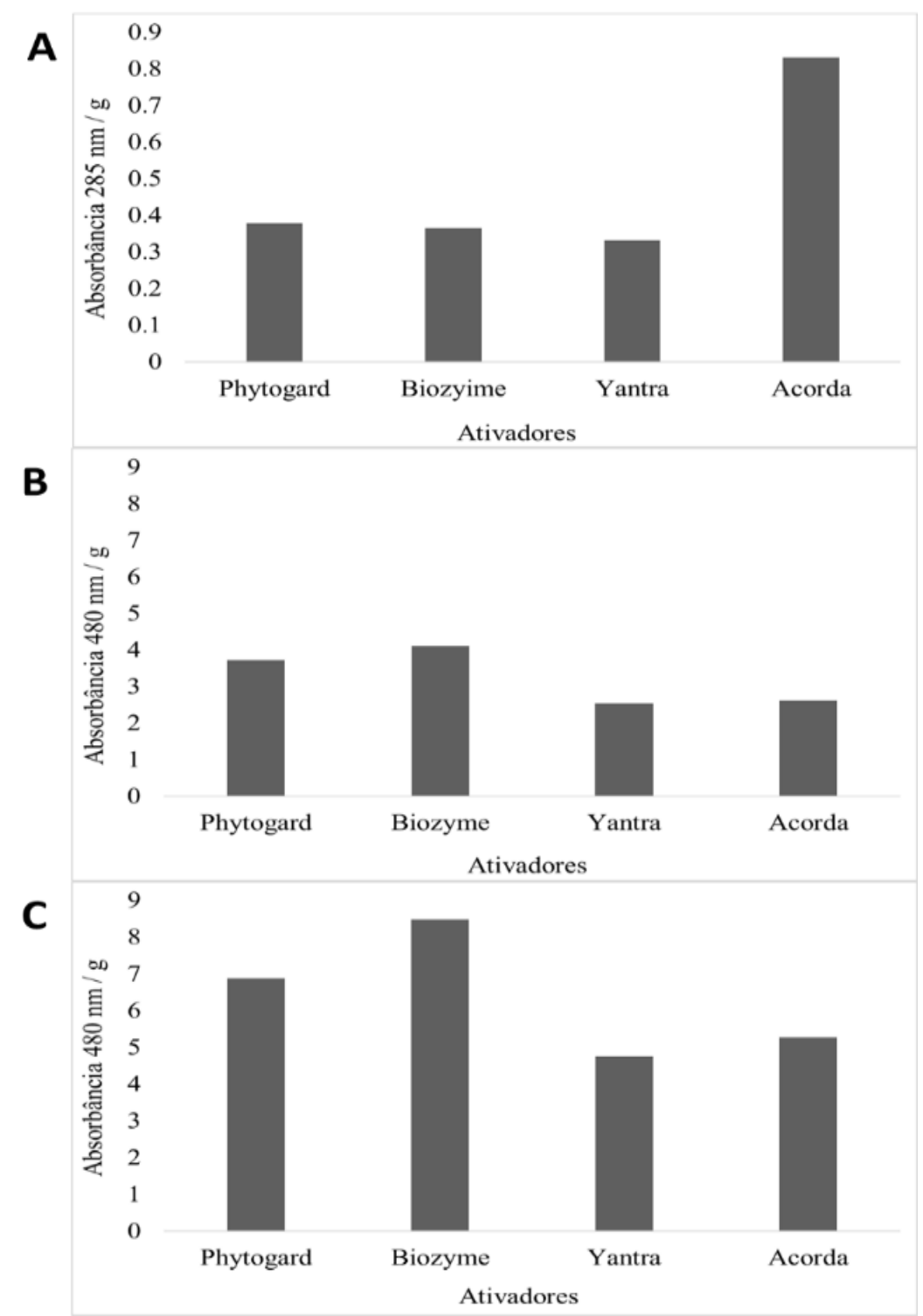

Figura 1 - (A) Produção de gliceolina em cotilédones de soja, (B) flavonoides 3-deoxiantocianidinas em mesocótilos de sorgo pela metodologia 1 (C) e metodologia 2, submetidos a tratamentos com indutores de resistência sistêmica comerciais. 


\section{Produção de fitoalexinas em cotilédones de soja}

Os testes realizados com Trichoderma sp., S. cerevisiae e $S$. boulardii neste trabalho mostraram que houve indução de gliceolina nos cotilédones de soja em todos os testes, sendo que quando submetidos à concentração $100 \%$, o Trichoderma sp. e $S$. cerevisiae foram mais eficientes e obtiveram valores semelhantes. Esses valores também foram similares à testemunha positiva (Figura 2).
O teste realizado com Trichoderma sp. apresentou o efeito dose-dependente com ajuste da equação de $1^{\circ}$ grau e $\mathrm{R}^{2}$ para 0,8745 , comprovando que a produção de gliceolina aumenta em função da concentração de células. Para $S$. boulardii, o efeito indutor somente ocorreu nas concentrações $0,5 \%$ e $100 \%$, sendo que as outras mostraram resultados semelhantes à testemunha negativa (Figura 2C).

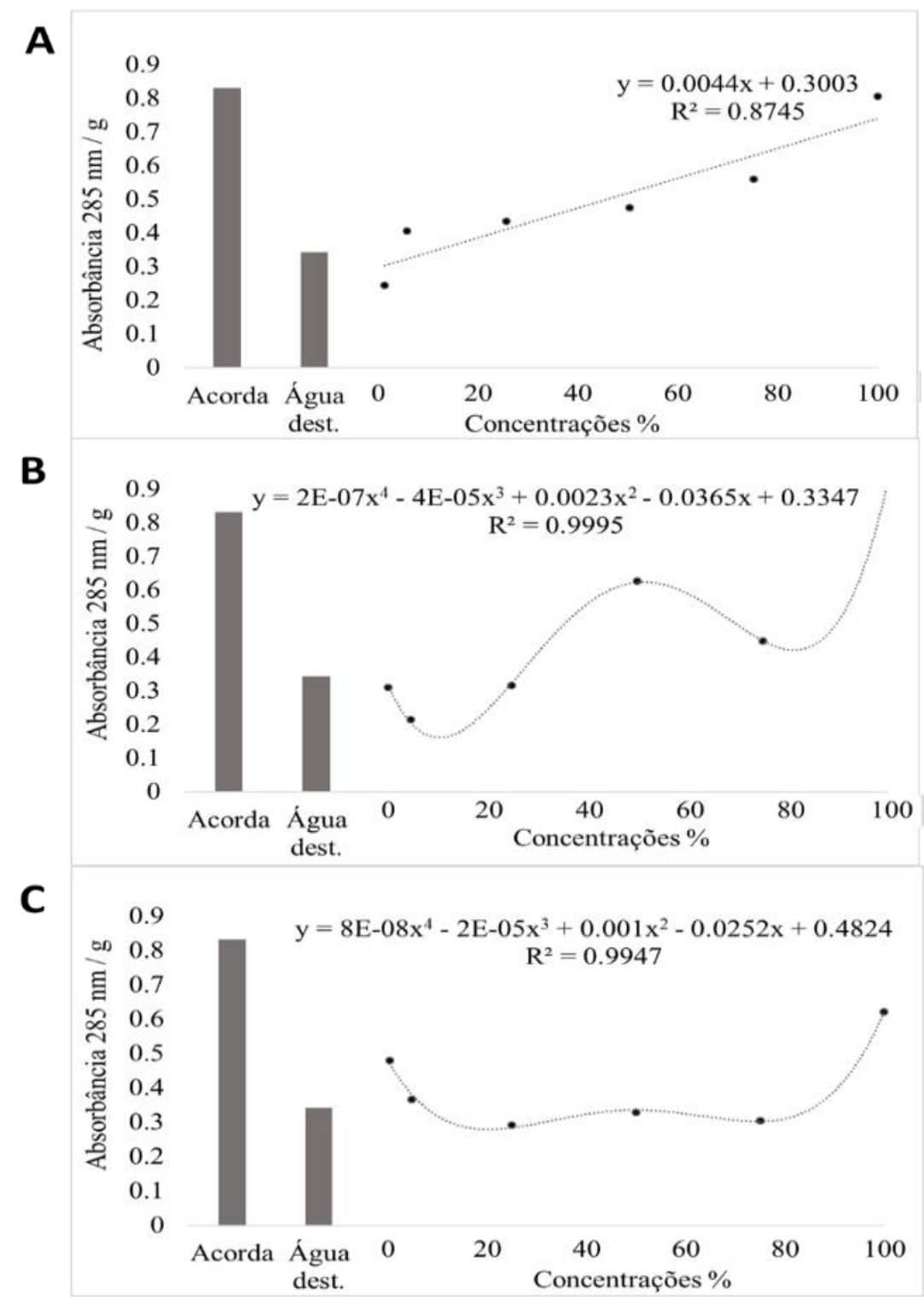

Figura 2 - (A) Produção de gliceolina em cotilédones de soja submetidos a tratamento com Trichoderma sp., (B) Sacharomyces cerevisiae (C) e Sacharomyces boulardii.

O ensaio feito com o óleo de C. citratus Stapf. apresentou efeito dose-dependente, com ajuste da equação de $1^{\circ}$ grau e $\mathrm{R}^{2}$ para 0,9049 . Dentre todas as concentrações testadas, $7500 \mu \mathrm{g} / \mathrm{mL}$ mostrou melhor resultado, com uma indução de fitoalexinas
$95,22 \%$ maior que a obtida no teste com a menor concentração. Além disso, a maior concentração de óleo de $C$. citratus Stapf. induziu 82,33\% mais fitoalexinas que à testemunha positiva (Figura 3 ). 


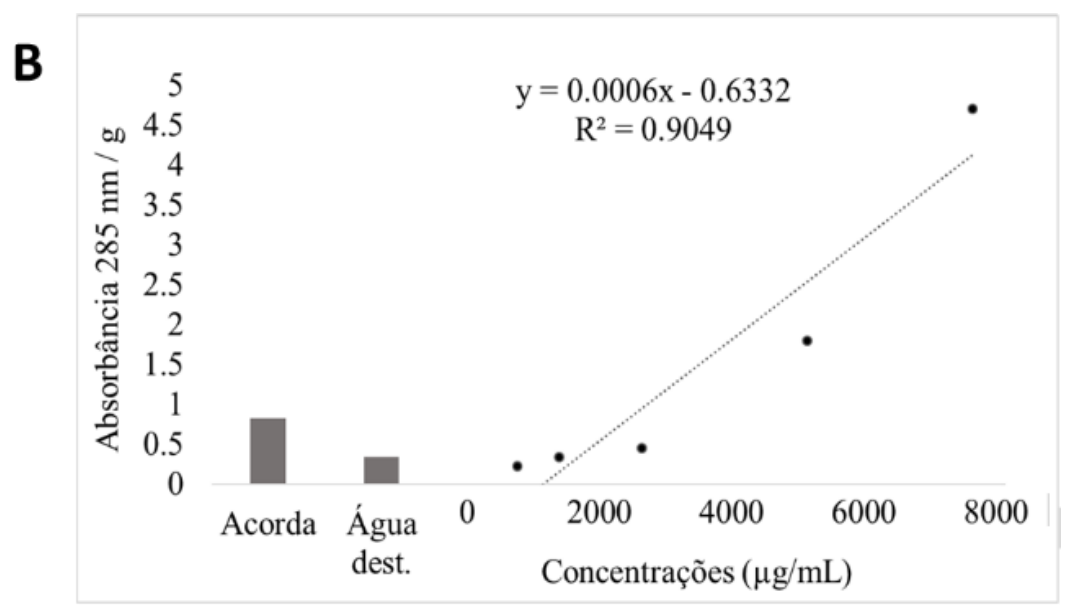

Figura 3 - Produção de gliceolina em cotilédones de soja submetidos a tratamento com óleo de Cymbopogon citratus Stapf.

Entre todos os eliciadores testados em cotilédones de soja, o que demonstrou melhor efeito de indução foi o óleo de $C$. citratus Stapf.

O óleo de C. citratus Stapf. foi o melhor eliciador em mesocótilos de sorgo, produzindo $73,33 \%$ mais flavonoides 3-deoxiantocianidinas que pela metodologia 1 na sua maior concentração.

Muitos trabalhos têm apresentado o potencial de células de leveduras, especialmente Sachamomyces sp., como eliciadoras na indução de fitoalexinas contra fitopatógenos em diversas plantas. Zanardo e seus colaboradores (2009) conseguiram demonstrar que a $S$. cerevisiae possui frações que podem ser utilizadas para a indução de resistência à antracnose, doença causada em pepinos pelo fungo Colletrotrichum lagenarium.

E estudos voltados para a cultura da cebola também mostraram uma moderada redução na severidade da doença ferrugem da Botrytis, causada por Botrytis allii, ao se utilizar a $S$. cerevisiae como um dos tratamentos. E o mesmo ocasionou um aumento significativo no teor total de fenol, indicando um correlação com a redução do desenvolvimento de patógenos, já que tais compostos são substancias tóxicas aos patógenos, outra possibilidade é a resistência ter sido gerada pela alteração do $\mathrm{pH}$ do citoplasma da célula vegetal, que é alterado com o aumento do conteúdo fenólico (Khaledi, Taheri, Tarighi2015; Hussein et al., 2018).

Em 2010, Stangarlin e seus colaboradores identificaram a levedura $S$. boulardii e seus derivados como capazes de induzir a produção de fitoalexinas em sorgo e soja. Alguns autores, sugerem também que o fungo Trichoderma sp. é capaz de produzir substâncias voláteis que inibem o crescimento micelial de uma diversidade de organismos causadores de doenças em plantas (Bomfim et al., 2010; Khaledi e Taheri, 2016), o que comprova os nossos resultados.

Quanto aos óleos essenciais, os que exibiram os melhores resultados em nossa pesquisa, são apresentados na literatura como um produto promissor no controle de doenças em várias culturas de plantas (de Souza Ferreira et al., 2018; Fira, Dimkić, Berić, Lozo e Stanković, 2018; Borah et al., 2019; Silva et al., 2019). Apesar das dificuldades de se testar esse produto no campo e do seu sistema de produção ainda ser limitado, os óleos possuem a vantagem de não oferecer risco à saúde humana e não promover contaminação ambiental (De Souza et al., 2019). Dessa forma, os óleos essenciais são uma alternativa ao uso de agrotóxicos (Amri, Hamrouni, Hanana, Jamoussi e Lebdi, 2014)

Especificamente o óleo de C. citratus Stapf. é rico em citral e limoneno. DeLima Guimarães e seus colaboradores (2011) confirmaram em seus estudos, que esses componentes possuem ação fungitóxica, corroborando com os resultados obtidos em nossas análises. Outro estudo comprovou a acentuada atividade antifúngica apresentada pelos óleos voláteis de $C$. citratus e Matricaria recutita, que quando comparados o óleo essencial do C. citratus Stapf. apresentou melhores resultados para o controle do crescimento micelial de Cladosporium cladosporioides (Dias, Lopes, Pinto, Moura e Nascimento, 2010).

Em 2008, Kumar e seus colaboradores apresentaram resultados que comprovaram a importância da característica hidrofóbica dos óleos essenciais e de seus constituintes na capacidade de interação com a camada lipídica das membranas celulares dos microrganismos. Essa característica é responsável por alterações na estrutura das membranas, causando a morte dos fungos (Kumar, Shukla, Singh, Prasad e Dubeyet, 2008). 


\section{Produção de fitoalexinas em mesocótilos de sorgo (metodologia 1)}

Os testes realizados com os microrganismos Trichoderma sp., S. cerevisiae e $S$. boulardii mostraram que todos produzem um efeito indutor, porém mais eficiente do que o causado na soja. Os resultados foram relativamente semelhantes para todas as concentrações de cada microrganismo. Nenhum dos eliciadores foi identificado como dose-dependente, porém, para $S$. cerevisiae e $S$. boulardii obteve-se melhores resultados nas suas maiores concentrações (Figura 4).

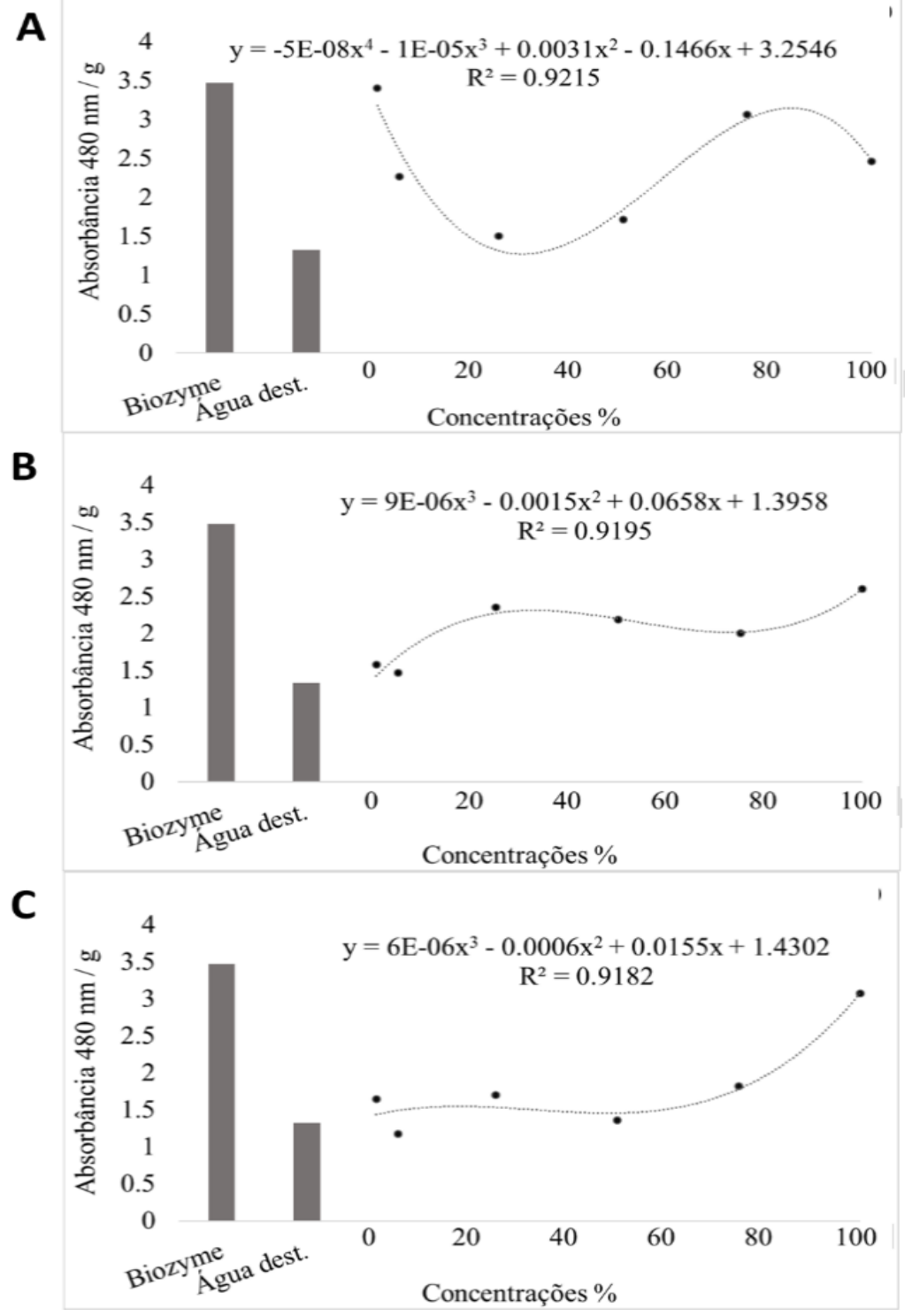

Figura 4 - (A) Produção de flavonoides 3-deoxiantocianidinas em mesocótilos de sorgo submetidos a tratamento com Trichoderma sp., (B) Sacharomyces cerevisiae (C) e Sacharomyces boulardii pela metodologia 1.

Assim como ocorreu nos testes com cotilédones de soja, todas as concentrações do óleo de C. citratus Stapf. mostraram efeito indutor, sendo caracterizado como dose-dependente, com ajuste da equação de $1^{\circ}$ grau e $\mathrm{R}^{2}$ para 0,8272 . Na concentração $7500 \mu \mathrm{g} / \mathrm{mL}$, o óleo de C. citratus Stapf. demons- trou efeito de indução muito maior que a testemunha positiva (Figura 5). 


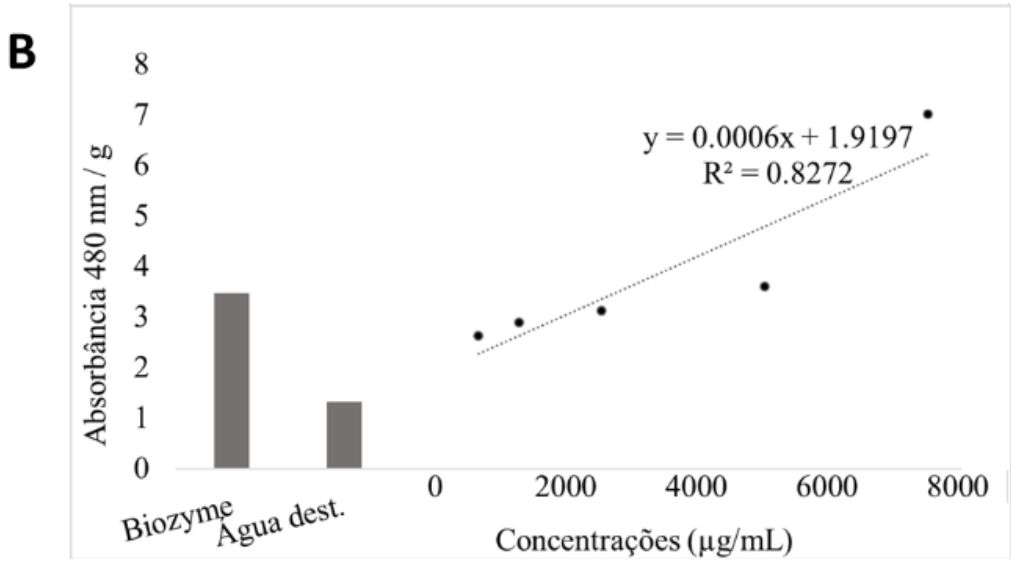

Figura 5 - Produção de flavonoides 3-deoxiantocianidinas em mesocótilos de sorgo submetidos a tratamento com óleo de Cymbopogon citratus Stapf. pela metodologia 1.

\section{Produção de fitoalexinas em mesocótilos de sorgo (metodologia 2)}

Nos testes com sorgo utilizando a segunda metodologia, observou-se a ocorrência de efeito indutor para os três tratamentos realizados em todas as concentrações. O melhor efeito indutor nesse caso foi o da S. boulardii na concentração $100 \%$, o qual apresentou acúmulo de 57,64\% mais fitoalexinas que à testemunha positiva. Apenas o teste feito com
S. boulardii apresentou efeito dose-dependente, com ajusta da equação de $1^{\circ}$ grau e $R^{2}$ para 0,802 (Figura 6).

Em comparação com a metodologia 1, os gráficos gerados para os tratamentos com $S$. cerevisiae e $S$. boulardii se comportaram de maneira relativamente semelhante, porém, o acúmulo de fitoalexinas foi muito maior na metodologia 2 (Figura $6 \mathrm{~B}$ e C).

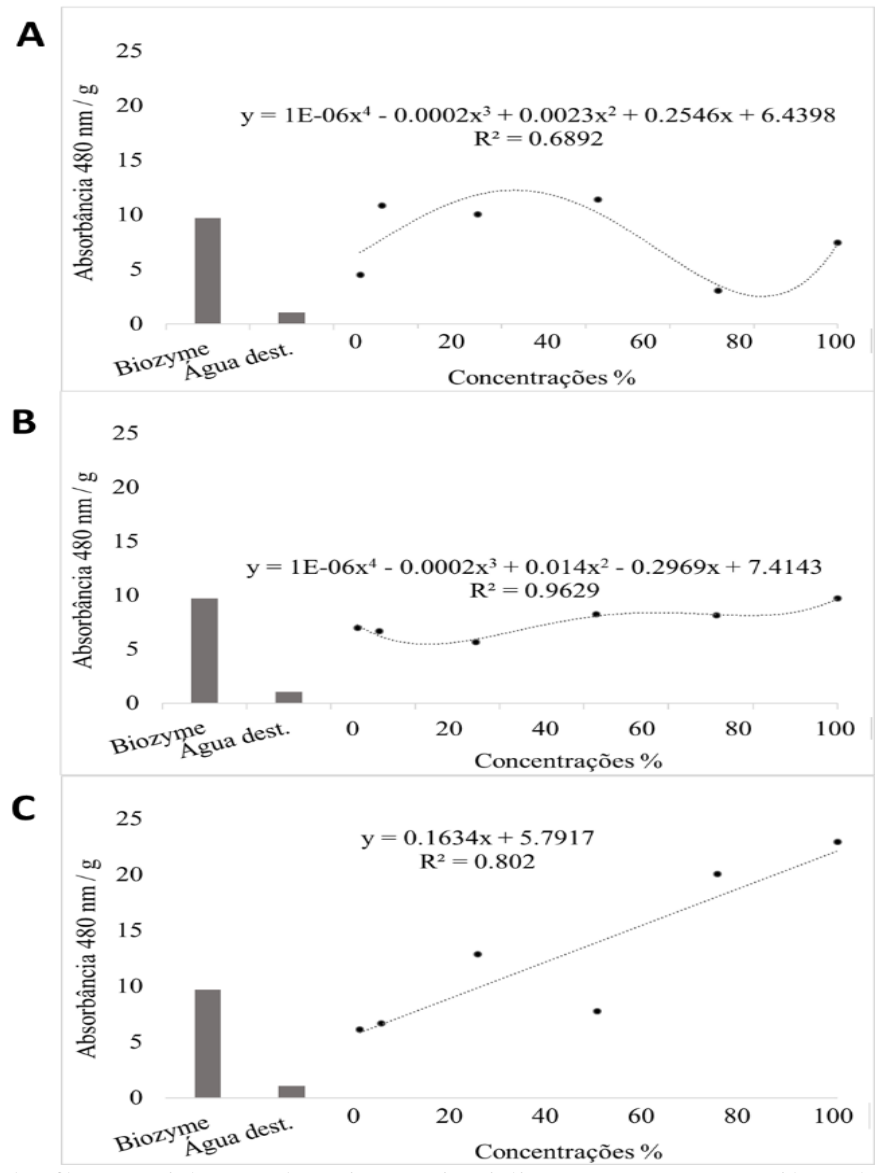

Figura 6 - (A) Produção de flavonoides 3-deoxiantocianidinas em mesocótilos de sorgo no tratamento com Trichoderma sp., (B) Sacharomyces cerevisiae (C) e Sacharommyces boulardii pela metodologia 2. 
Para os testes com o óleo essencial, não houve efeito dose-dependente. Todas as concentrações foram capazes de induzir produção de fitoalexinas em sorgo, sendo que a maior concentração apresentou valor $63,08 \%$ maior que à testemunha positiva (Figura 7). Entretanto, os tratamentos com maiores concentrações $(5000$ e $7500 \mu \mathrm{g} / \mathrm{mL})$ do óleo de $C$. citratus Stapf. causaram inibição no crescimento da planta, indicando que essas concentrações são inviáveis para o controle de patógenos em plantas por causa de sua fitotoxicidade (Figura 8).

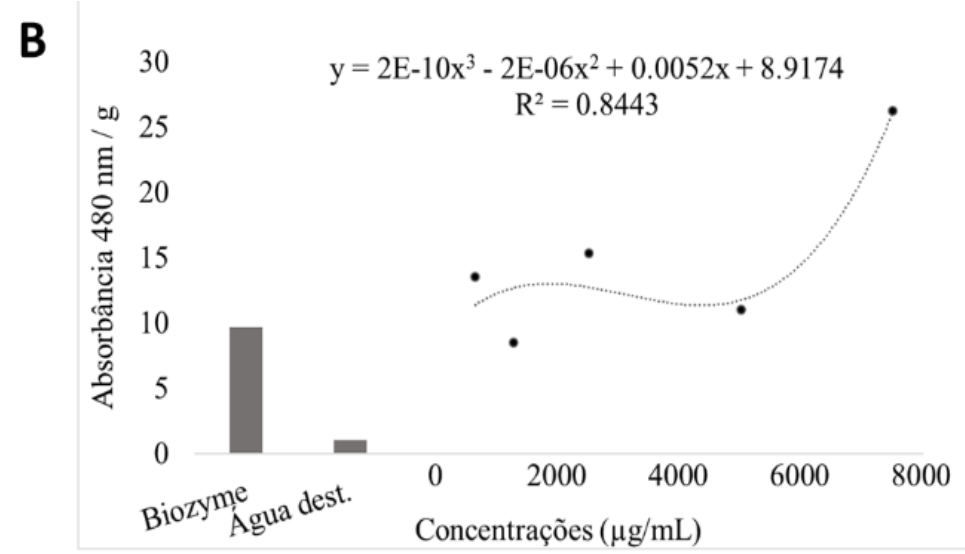

Figura 7 - Produção de flavonoides 3-deoxiantocianidinas em mesocótilos de sorgo submetidos a tratamento com óleo de Cymbopogon citratus Stapf. pela metodologia 2.

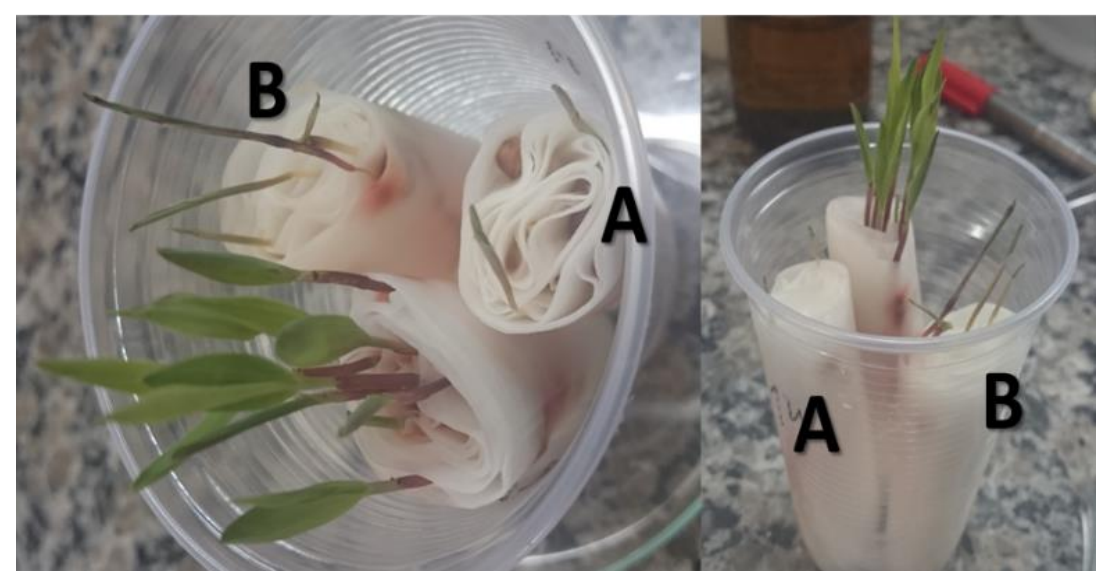

Figura 8 - (A) Plântulas de sorgo submetidas à concentração de 5000 e (B) $7500 \mu \mathrm{g} / \mathrm{mL}$ de óleo de Cymbopogon citratus Stapf.

Geralmente, a produção de fitoalexinas em mesocótilos de sorgo ocorre em função do aumento da concentração de células de $S$. cerevisiae presentes nas preparações. Todavia, Wulff e Pascholati (1999) observaram em seus experimentos que um comportamento não linear ocorreu em resposta ao aumento de concentração das frações parcialmente purificadas da levedura. Apesar desde comportamento, foi possível observar que a produção de fitoalexinas em sorgo é maior na concentração mais alta.

O teste de indução de fitoalexinas em sorgo pela metodologia 2 se mostrou mais eficiente no acúmulo dessas substâncias. Provavelmente, essa eficiência se deve ao fato de que os tratamentos foram aplicados às plântulas em desenvolvimento, fa- zendo com que elas demonstrassem um comportamento mais próximo do que possivelmente ocorreria se a aplicação fosse feita no campo. Além disso, fazendo uso dessa metodologia foi possível observar o comportamento da planta em relação aos tratamentos aplicados, podendo avaliar se o tratamento seria viável ou não.

\section{CONCLUSÕES}

Os eliciadores testados neste trabalho promoveram o acúmulo de fitoalexinas em cotilédones de soja e mesocótilos de sorgo. O tratamento que mais induziu resistência em ambas as culturas foi o óleo essencial de $C$. citratus Stapf., porém foi observado uma inibição no crescimento do sorgo submetido à altas concentrações deste óleo na metodologia 2 . A 
metodologia 2 para indução de fitoalexinas em sorgo gerou melhores resultados quando comparada com a metodologia 1 devido ao grande acúmulo de flavonoides 3-deoxiantocianidinas e à possibilidade de observação da reação da plântula à cada tratamento.

\section{AGRADECIMENTOS}

Os autores agradecem o suporte da Universidade Federal do Tocantins na realização da pesquisa.

\section{REFERÊNCIAS BIBLIOGRÁFICAS}

AMRI, I.; HAMROUNI, L.; HANANA, M.; JAMOUSSI, B.; LEBDI, K. Essential oils as biological alternatives to protect date palm (Phoenix dactylifera $\mathrm{L}$.) against Ectomyelois ceratoniae Zeller (Lepidoptera: Pyralidae). Chilean journal of agricultural research, 74(3), 273-279, 2014. http://dx.doi.org/10.4067/S0718-58392014000300004

BAZARGANI, M.; ROHLOFF, J. (2016). Antibiofilm activity of essential oils and plant extracts against Staphylococcusaureus and Escherichia coli biofilms. Food Control, 61, 156-164. https://doi.org/10.1016/j.foodcont.2015.09.036

BOMFIM, M.P.; SÃO JOSÉ, A.R.; REBOUÇAS, T.N.H.; de ALMEIDA, S.S.; SOUZA, I.V.B.; DIAS, N.O. (2010). Avaliação antagônica in vitro e in vivo de Trichoderma spp. a Rhizopus stolonifer em maracujazeiro amarelo Antagonic effect in vitro and in vivo of Trichoderma spp. to Rhizopus stolonifer in yellow passion fruit. Summa Phytopathologica, 36(1), 61-67. https://doi.org/10.1590/S010054052010000100011

BONALDO, S. Efeito de Saccharomyces cerevisiae na síntese de fitoalexinas em sorgo, na germinação e formação de apressórios por fungos fitopatogênicos e na proteção de pepino a Colletotrichum lagenarium e sorgo a Colletotrichum sublineolum. 2005. 166f. Tese de Doutorado (Agronomia) - Universidade de São Paulo, Piracicaba, 2005.

BORAH, A.; PAW, M.; GOGOI, R.; LOYING, R.; SARMA, N.; MUNDA, S.; LAL, M. Chemical composition, antioxidant, anti-inflammatory, anti-microbial and in-vitro cytotoxic efficacy of essential oil of Curcuma caesia Roxb. leaves: An endangered medicinal plant of North East India. Industrial Crops and Products, 129, 448-454, 2019. https://doi.org/10.1016/j.indcrop.2018.12.035

COSTA, G.; FERREIRA, J.P.; VITORINO, C.; PINA, M.E.; SOUSA, J.J.; FIGUEIREDO, I.V.; BATISTA, M.T. Polyphenols from Cymbopogon citratus leaves astropicais anti-inflammatory agents. Journal of ethnopharmacology, 178, 222-228, 2016.

https://doi.org/10.1016/j.jep.2015.12.016

De LIMA GUIMARÃES, L.G.; das GRAÇAS, C.M.; SOUZA, P.E., de ANDRADE, J.; VIEIRAS, S. Atividades antioxidante e fungitóxica do óleo essencial de capim-limão e do citral. Revista Ciência Agronômica, 42(2), 464472, 2011.

De SOUZA FERREIRA, T.P.; MOURÃO, D.D.S.C.; dos SANTOS, G.R.; de LIMA GUIMARÃES, L.G.; PIRES
E.C. F.; SANTOS, W.F.; de SOUZA AGUIAR, R.W. Fungistatic activity of essential oil of Lippia sidoides Cham. against Curvularia lunata. African Journal of Agricultural Research, 13(14), 704-713, 2018. doi: 10.5897/AJAR2018.12977.

De SOUZA, M.F.C.; PENTEADO, A.L., de SOUZA, D.R.C.; de QUEIROZ, S.C.D.N. Atividade antimicrobiana "in vitro" de óleos essenciais contra patógenos de peixes/" In vitro" antimicrobian activity of essential oils against fish pathogens. Brazilian Journal of Development, 5(10), 17911-17921, 2019.

DIAS, L.P.; LOPES, A.S.; PINTO, C.E.M.; MOURA, H.F.N.; NASCIMENTO, V.L.V. Fungitoxidade do óleo essencial do capim-limão (Cymbopogon citratus) e da camomila (Matricaria recutita) sobre o fitopatógeno Cladosporium cladosporioides. Instituto Federal de Educação, Ciência e Tecnologia do Piauí. V CONNEPI-2010. 2010.

DORMAN, H.J.D.; DEANS, S.G. Antimicrobial agents from plants: antibacterial activity of plant volatile oils. Journal of Applied Microbiology, 88(2), 308-316, 2000. https://doi.org/10.1046/j.1365-2672.2000.00969.x

EJIKE, C.E.; GONG, M.; UDENIGWE, C.C. Phytoalexins from the Poaceae: Biosynthesis, function and prospects in food preservation. Food research international, 52(1), 167 177, 2013. https://doi.org/10.1016/j.foodres.2013.03.012

FADINI, M.A.; LEMOS, W.P.; PALLINI, A.; VENZON, M.; MOURÃO, S.A. Herbivoria de Tetranychus urticae Koch (Acari: Tetranychidae) induz defesa direta em morangueiro?. Embrapa Amazônia Oriental-Artigo em periódico indexado (ALICE). 2004.

FIRA, D.; DIMKIĆ, I.; BERIĆ, T.; LOZO, J.; STANKOVIĆ, S. Biological control of plant pathogens by Bacillus species. Journal of biotechnology, 285, 44-55, 2018. https://doi.org/10.1016/j.jbiotec.2018.07.044

GUIMARÃES LGDL, CardosoMDG, Zacaroni LM, Lima RK, PimentelFA, Morais AR. Influência da luz e da temperatura sobre a oxidação do óleo essencial de capim-limão (Cymbopogon citratus (DC) Stapf). Quim Nova, 31(6), 1476-1480, 2008.

HUSSEIN, M. M.; ABO-ELYOUSR, K. A.; HASSAN, M. A.; HASHEM, M.; HASSAN, E. A.; ALAMRI, S. A. Induction of defense mechanisms involved in disease resistance of onion blight disease caused by Botrytis allii. Egyptian Journal of Biological Pest Control, 28(1), 80, 2018. https://doi.org/10.1186/s41938-018-0085-5

KHALEDI, N.; TAHERI, P.; TARIGHI, S. Antifungal activity of various essential oils against Rhizoctonia solani and $\mathrm{M}$ acrophomina phaseolina as maiores bean pathogens. Journal of applied microbiology, 118(3), 704-717, 2015. https://doi.org/10.1111/jam.12730

KHALEDI, N.; TAHERI, P. Biocontrol mechanisms of Trichoderma harzianum against soybean charcoal rot caused by Macrophomina phaseolina. Journal of Plant Protection Research, 56(1), 21-31, 2016. https://doi.org/10.1515/jppr-2016-0004

KUMAR, A.; SHUKLA, R.; SINGH, P.; PRASAD, C.S.; DUBEY, N.K. Assessment of Thymus vulgaris L. essential oil as a safe botanical preservative against post harvest fun- 
gal infestation of food commodities. Innovative food science \& emerging technologies, 9(4), 575-580, 2008.

https://doi.org/10.1016/j.ifset.2007.12.005

MEINERZ, C.C.; FORMIGHIERI, A.P.; SCHWAN-ESTRADAK, R.F.; DIETERIC, H.C.; FRANZENER, G.; STANGARLIN, J.R. Atividade elicitora de fitoalexinas em sorgo e soja por derivados de avenca (Adiantum capillusveneris L.). Rev. Bras. Plantas Med, 10(2), 26-31, 2008.

MOTOYAMA, M.M.; SCHWAN-ESTRADA, K.R.F.; STANGARLIN, J.R.; FIORI-TUTIDA, A.C.G.; SCAPIM, C. A. Indução de fitoalexinas em soja e em sorgo e efeito fungitóxico de extratos cítricos sobre Colletotrichum lagenarium e Fusarium semitectum. Acta Scientiarum. Agronomy, 25(2), 491-496, 2003. http://dx.doi.org/10.4025/actasciagron.v25i2.2062

NICHOLSON, R.L.; JAMIL, F.F.; SNYDER, B.A.; LUE, W.L.; HIPSKIND, J. Phytoalexin synthesis in the juvenile sorghum leaf. Physiological and Molecular Plant Pathology, 33(2), 271-278, 1988. https://doi.org/10.1016/08855765(88)90027-6

PEDRAS, M.S.C.; AHIAHONU, P.W. Metabolism and detoxification of phytoalexins and analogs by phytopathogenic fungi. Phytochemistry, 66(4), 391-411, 2005. https://doi.org/10.1016/j.phytochem.2004.12.032

PETERS, R.J. Uncovering the complex metabolic network underlying diterpenoid phytoalexin biosynthesis in rice and other cereal crop plants. Phytochemistry, 67(21), 23072317, 2006. https://doi.org/10.1016/j.phytochem.2006.08.009

SILVA, D.C.; ARRIGONI-BLANK, F.M.; BACCI, L.; BLANK, A.F.; FARO, R.R.N.; PINTO, J.A.O.; PEREIRA, K.L.G. Toxicidade e alterações comportamentais de óleos essenciais de genótipos de Eplingiellafruticosa e seus principais compostos para Acromyrmex balzani. Crop Protection, 116, 181-187, 2019. https://doi.org/10.1016/j.cropro.2018.11.002

STANGARLIN, J.R.; SCHULZ, D.G.; FRANZENER, G.; ASSI, L.; SCHWAN-ESTRADA, K.R.F.; KUHN, O.J. Indução de fitoalexinas em soja e sorgo por preparações de Saccharomyces boulardii. Arquivos do Instituto Biológico, São Paulo, 77(1), 91-98, 2010.

TAMM, L.; THÜRIG, B.; FLIESSBACH, A.; GOLTLIEB, A.E.; KARAVANI, S.; COHEN, Y. Elicitors and soil management to induce resistance against fungal plant diseases. NJAS-Wageningen Journal of Life Sciences, 58(34), 131-137, 2011. https://doi.org/10.1016/j.njas.2011.01.001

THALER, J.S.; FIDANTSEF, S.S.; DUFFEY; R.M. BOSTOCK. Trade-offs in plant defense against pathogens and herbivores: a field demonstration of chemical elicitors of induced resistance. J. Chem. Ecol. 25: 1597-1609, 1999.

WULFFNA, PASCHOLATISF. Partial characterization of sorghum phytoalexin elicitors isolated from Saccharomyces cerevisiae. Fitopatologia Brasileira, 24(3), 428435, 1999.

ZANARDONMT, PASCHOLATISF, FIALHO MB. Resistência de plântulas de pepineiro $a$ Colletotrichum lagenarium induzida por frações de extrato de Saccharomyces cerevisiae. Pesquisa Agropecuária Brasileira, 44(11), 14991503, 2010. 